4. Holroyd GL, Conway CJ, Trefry HE (2011) Breeding Dispersal of a Burrowing Owl from Arizona to Saskatchewan. The Wilson Journal of Ornithology 123:378-381.

5. Federation of Alberta Naturalists (2007) The Atlas of Breeding Birds of Alberta, a second look. Federation of Alberta Naturalists, Edmonton, AB.
- Helen E. Trefry ${ }^{1}$, Geoffrey L. Holroyd

Environment Canada, Room 200, 4999-

98 Ave, Edmonton, Alberta, T6B 2X3

${ }^{1} E$-mail: <helen.trefry@ec.gc.ca>

\title{
THE ALFRED HUBBARD AND FAMILY ALBERTA WILDLIFE COLLECTION-AUNIQUE SHOWCASE OF THE BIODIVERSITY OF THE CANADIAN PRAIRIES
}

The Alfred Hubbard and Family Alberta Wildlife Collection was established in 2007 in the ground floor of the Cousins Science Building of Lethbridge College, and is one of the largest museum collections of native wildlife species displays in Western Canada. What started as a small private collection has extended into a noteworthy and prestigious assembly. The collection showcases a wide diversity of mammals of Alberta, and a large collection of avian species including native wild species, game birds, and an impressive collection of raptors. The wild bird species collection includes woodland, boreal forest, and prairie grassland species, as well as representative waterfowl of the province. The Hubbard Wildlife Collection showcases a diverse spectrum of attractive museum displays, such as grizzly bear, black bear, prairie bison, cougar, big horn sheep, mountain goat, badger, beaver (the national animal of Canada and also present in the coat of arms for the province of Alberta), lynx, bobcat, silver fox, coyote, white-tailed deer, mule deer, caribou, elk, moose, pronghorn, wolf, prairie bison, and wolverine. Housed on the ground floor, it attracts a large number of visitors to the galleries, including school children, postsecondary students, university students, wildlife enthusiasts, researchers, and tourists. The collection is also central to the Environmental Science academic program at Lethbridge College.

The Hubbard Wildlife Collection offers regular tours by knowledgeable staff members. Tours can be booked by calling 403-320-3202 Extension 5594. The species collections are also viewable online at http://www.lcvirtualwildlife.com. This site is officially known as the Virtual Wildlife Project, and is the electronic archive of the Hubbard Wildlife Collection. The site contains detailed information about different wildlife species based on peer-reviewed research, several videos, and other related multimedia files associated with wildlife ecology, behavior, habitats and biodiversity, animal tracks and signs for identification, and exciting games. The website is a spectacular interactive and informative tool attractive to $\mathrm{K}-12$ and post-secondary students, a long-term dream and goal of its donor Alfred Hubbard. Well documented, latest taxonomic classifications of individual species from the collection are provided. 
Individual species are provided with a three-dimensional image of the specimen and the skull, related videos, audio files, images, tracks and signs, and status maps when information is available. One of the interesting features that attracts online visitors to the site is the portal on learning activities. The learning activities icon covers a diverse range of ecological information on the target wildlife species, which is based on research and peerreviewed wildlife literature. This unique collection will educate and inspire generations of students (young and old) and will continue to cater not just to Alberta, but to all of Western Canada.

- Saikat Kumar Basu, School of Agriculture and Life Sciences, Center for Applied Arts and Sciences, Lethbridge College, 3000 College Drive South Lethbridge, AB T1K 1L6; E-mail: <saikat.basu@ lethbridgecollege.ca>

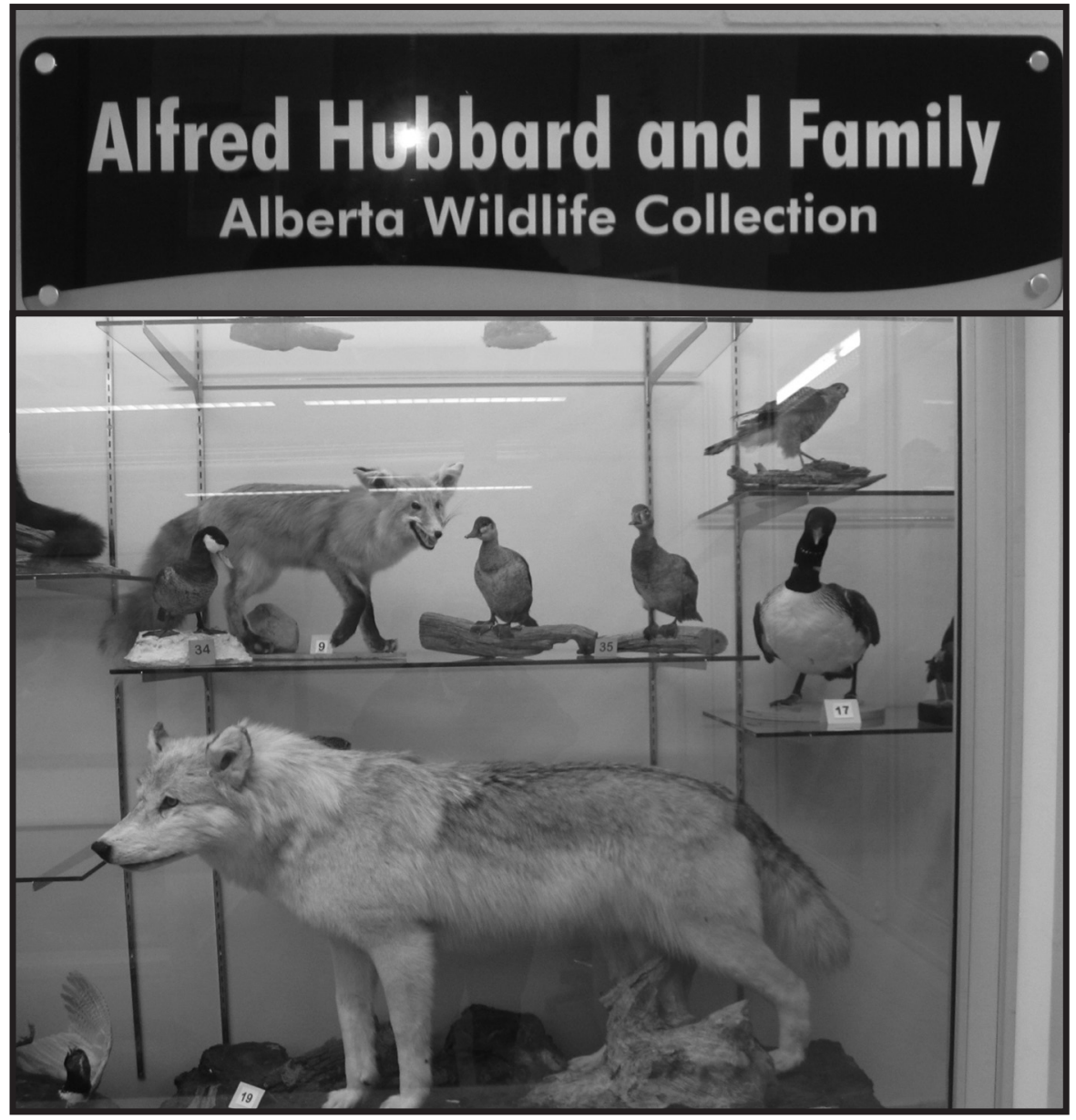

One of the display cases at the Alfred Hubbard and Family Alberta Wildlife Collection, Lethbridge College, illustrating the diversity of specimens displayed at this facility. Photo by Saikat Basu. 